Article

\title{
Comparing Built-in Power Banks for a Smart Backpack Design Using an Auto-Weighting Fuzzy-Weighted-Intersection FAHP Approach
}

\author{
Hsin-Chieh $\mathrm{Wu}^{1}{ }^{1}$, , Tin-Chih Toly Chen ${ }^{2, *}$, Chin-Hau Huang ${ }^{2}$ and Yun-Cian Shih ${ }^{2}$ \\ 1 Department of Industrial Engineering and Management, Chaoyang University of Technology, \\ Taichung 413310, Taiwan; hcwul@cyut.edu.tw \\ 2 Department of Industrial Engineering and Management, National Chiao Tung University, \\ 1001, University Road, Hsinchu 30010, Taiwan; sasa76130@hotmail.com (C.-H.H.); \\ winnie22822@gmail.com (Y.-C.S.) \\ * Correspondence: tolychen@ms37.hinet.net
}

Received: 18 September 2020; Accepted: 11 October 2020; Published: 13 October 2020

\begin{abstract}
Smart backpacks are a prevalent application of smart technologies, with functions such as motion recording, navigation, and energy harvesting and provision. Selecting a suitable built-in power bank is a critical task for a smart backpack design, which has rarely been investigated in the past. To fulfill this task, an auto-weighting fuzzy-weighted-intersection fuzzy analytic hierarchy process (FAHP) approach is proposed in this study. When decision makers lack an overall consensus, the auto-weighting fuzzy-weighted-intersection FAHP approach specifies decision makers' authority levels according to the consistency ratios of their judgments. In this way, the consensus among all decision makers can be sought. The auto-weighting fuzzy-weighted-intersection FAHP approach has been applied to compare six mobile power banks for a smart backpack design.
\end{abstract}

Keywords: smart backpack; fuzzy weighted intersection; authority level; consensus; fuzzy analytic hierarchy process

\section{Introduction}

Some research results have shown that smart technologies can improve the quality of life of users [1-4]. Among the existing smart technology applications, smart backpacks have considerable potential, because the existing market for backpacks is huge [5]. However, the development of smart backpacks is not yet mature. In addition, the existing smart backpack designs, such as the applied smart technology, embedding location, and cost effectiveness, have rarely been optimized [6]. In order to fill this gap, the problem of selecting the most suitable built-in power bank for a smart backpack design is investigated in this study, in which the suitability of the built-in power bank is optimized. To this end, an auto-weighting fuzzy-weighted-intersection fuzzy analytic hierarchy process (FAHP) approach is proposed in this study. The motives are explained as follows.

Selecting the most suitable built-in power bank for a smart backpack design is obviously a multiple-criteria decision-making problem [7] to which FAHP is a widely applied method $[8,9]$. The incorporation of fuzzy logic is to consider the uncertainty inherent in the selection process $[10,11]$, since the development of smart backpacks is still in its infancy. In addition, multiple decision makers are involved in the selection process to avoid personal bias and consider various viewpoints [12-15]. As a result, the proposed methodology is a group-based FAHP method $[16,17]$.

In the existing group-based FAHP methods, the consensus among decision makers is assumed to exist, and can be derived by calculating the fuzzy arithmetic average [18] or fuzzy geometric mean (FGM) [19] of decision makers' pairwise comparison results [20]. However, the application of fuzzy 
arithmetic average may lead to illogical results [21], while the application of FGM may generate results that are unacceptable to decision makers [22]. To solve these problems, three fuzzy intersection (FI) operators FI [23], partial-consensus FI (PCFI) [11,24,25], and fuzzy weighted intersection (FWI) [22], are applied to aggregate decision makers' judgments in the proposed methodology. If all decision makers reach an overall consensus, FI is applied to aggregate the relative priorities derived by them. Otherwise, PCFI is applied to seek the partial consensus among most of the decision makers instead [26,27]. However, the number of decision makers that reach a consensus is reduced, which is not welcome to decision makers. To address this issue, the fuzzy weighted intersection (FWI) operator proposed by Chen et al. [22] is applicable.

The novelty of the proposed methodology resides in the following:

(1) A systematic procedure is established to guide when the three FI operators should be applied.

(2) In Chen et al. [22], FWI is applied to consider decision makers' unequal authority levels, while in this study FWI is used as an alternative to PCFI.

(3) In addition, an auto-weighting mechanism is proposed to assign virtual weights to decision makers.

The auto-weighting fuzzy-weighted-intersection FAHP approach is applied to compare several built-in power banks for a smart backpack design to illustrate its effectiveness.

The remainder of this paper is organized as follows. Section 2 is dedicated to the literature review. Section 3 introduces the auto-weighting fuzzy-weighted-intersection FAHP approach. Section 4 details the application of the auto-weighting fuzzy-weighted-intersection FAHP approach to compare several built-in power banks for a smart backpack design. Based on the experimental results, a comparison with existing methods is also made. Section 4 concludes this study and puts forth some topics for further investigation.

\section{Literature Review}

\subsection{Smart Backpacks}

A smart backpack, also known as an augmented backpack, is an innovative application of smart technologies to backpacks $[5,7,28,29]$. A smart backpack has functions such as motion recording, navigation, and energy harvesting and provision [7]. At present, most of the smart backpacks on the market focus on the energy harvesting and providing function [29]. There are three main ways for smart backpacks to provide electricity: external solar panels, built-in power banks, and generating electricity from friction. Among them, built-in power banks are the most prevalent way [29].

Lee et al. [30] designed a smart backpack for the visually impaired, which was equipped with ultrasonic sensors on the straps, so as to detect obstacles in front of a user to issue a warning. In addition, when used indoors, the smart backpack was also equipped with a Zigbee (Xbee) module that sent signals to multiple Zigbee landmarks/receivers. According to the strengths of the signals received by different Zigbee landmarks, the user could be located [31,32].

Chandrasekhar et al. [33] embedded a triboelectric nanogenerator into a self-made smart backpack to generate electricity from the motions of the backpacker. They also observed the output voltage with respect to different human motions and backpack weights. The experimental results showed that the higher the weight of the backpack, the greater the output voltage generated. In addition, a more intense action (running $>$ walking $>$ bending over) generated a greater output voltage.

Cruz et al. [34] also designed a smart backpack for the visually impaired. Its functions were mainly for indoor positioning. First, an attached photoelectric sensor detected whether there were obstacles in front of the backpacker. Second, the Zigbee module and receiver were used for user positioning. Third, a built-in radio frequency identification (RFID) receiver received signals from RFID tags of surrounding objects. Then, the backpacker was informed of the positioning result by the built-in vibrators in the straps. The names of surrounding objects were also voiced to the backpacker. The simultaneous application of multiple positioning functions was to improve the accuracy of positioning. 
Sankhe and Rodrigues [35] designed a smart backpack with three smart functions: the detection of obstacles in front (using ultrasonic sensors), automatic travelling (by driving the wheels so that the backpack moved forward by itself), and LED light warning.

\subsection{FAHP Applications to Smart Backpacks}

Subsequently, some applications of FAHP to smart backpacks are reviewed. In the view of Wu et al. [36], the five key factors affecting a smart backpack design were fashionable design, cheap price, many smart functions, high practicality, and light weight. Wu et al. proposed an FAHP method to compare the relative priorities of these critical factors.

Lin and Chen [7] proposed a multibelief analytic hierarchy process and nonlinear programming approach that was able to decompose a less consistent judgment matrix into several more consistent sub-judgment matrixes. The relative priority sets generated from these sub-judgment matrixes were very different from each other. Based on them, diversified smart backpack designs could be made $[37,38]$.

In this study, the FWI operator proposed by Chen et al. [22] is incorporated into FAHP to select the most suitable built-in power bank for a smart backpack design. The FWI operator was originally designed for aggregating decision makers' judgments when they had unequal authority levels. However, an interesting property of FWI is that the aggregation result may not be an empty set even if decision makers lack an overall consensus, as illustrated in Figure 1. Therefore, by applying FWI instead of PCFI, it is no longer necessary to reduce the number of decision makers that reach a consensus. However, a prerequisite for applying FWI is that decision makers have unequal authority levels. If decision makers do not discriminate their authority levels, then a reasonable treatment is to assign the authority levels (or weights) of decision makers automatically based on the consistency ratios (CRs) of their pairwise comparison results. From this point of view, an auto-weighting fuzzy-weighted-intersection FAHP approach is proposed in this study.

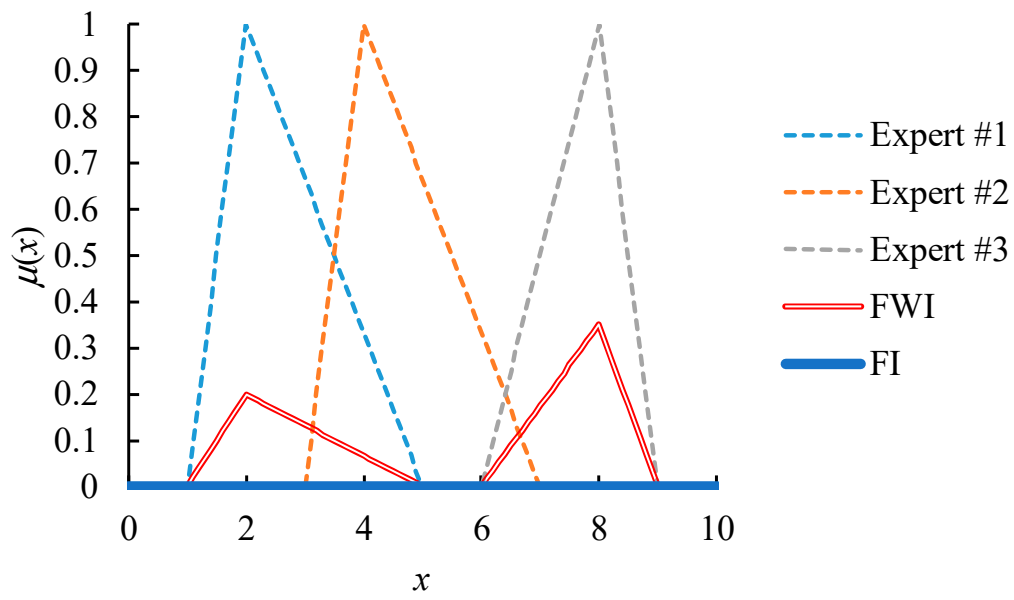

Figure 1. The fuzzy weighted intersection (FWI) result when decision makers lack an overall consensus.

\section{Methodology}

\subsection{Implementation Procedure}

The auto-weighting fuzzy-weighted-intersection FAHP approach is proposed in this study for comparing built-in power banks for a smart backpack design. The operational procedure of the auto-weighting fuzzy-weighted-intersection FAHP approach comprises the following steps:

Step 1. Each decision maker applies the FGM method $[1,19,39,40]$ to evaluate the relative priorities of factors critical to a built-in power bank for a smart backpack design.

Step 2. Evaluate the CR of the judgment matrix by each decision maker. 
Step 3. Apply FI [23] to aggregate the relative priorities evaluated by decision makers.

Step 4. If all decision makers reach an overall consensus, go to Step 7; otherwise, go to Step 5.

Step 5. Calculate the authority level (or weight) of each decision maker.

Step 6. Apply FWI [22] to aggregate the relative priorities.

Step 7. Applying the fuzzy technique for order preference by similarity to ideal solution (FTOPSIS) approach $[18,40-42]$ to assess the overall performance of a built-in power bank for a smart backpack design.

Step 8. Applying the center-of-gravity (COG) method $[36,43,44]$ to defuzzify the assessment result, so as to generate an absolute ranking of built-in power banks for a smart backpack design.

A flowchart is provided in Figure 2 to illustrate the operational procedure.

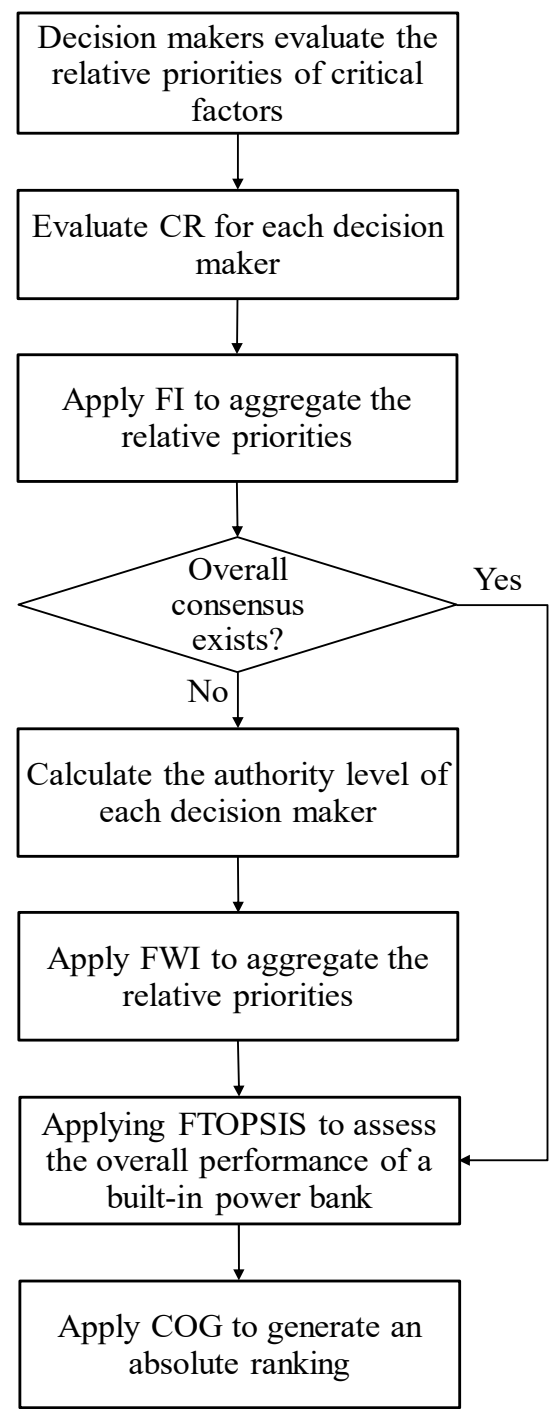

Figure 2. Operational procedure of the auto-weighting fuzzy-weighted-intersection fuzzy analytic hierarchy process (FAHP) approach.

\subsection{Evaluating the Relative Priorities of Critical Factors}

In the proposed methodology, at first, each decision maker evaluates the relative priorities of critical factors in pairs using the FGM method. The comparison results are expressed in linguistic terms such as "as equal as", "weakly more important than", "strongly more important than", "very strongly more important than", "absolutely more important than", etc. These linguistic terms are usually 
mapped to triangular fuzzy numbers (TFNs) within [1,9,19]. Chen [45] widened these TFNs to increase the possibility for decision makers to reach a consensus. To the contrary, Samanlioglu and Kaya [46] narrowed these TFNs to elevate the consistency of pairwise comparison results.

Based on pairwise comparison results, a fuzzy judgment matrix $\tilde{\mathbf{A}}_{n \times n}=\left[\widetilde{a}_{i j}\right]$ is constructed, in which

$$
\tilde{a}_{j i}=1 / \widetilde{a}_{i j}
$$

The fuzzy eigenvalue and eigenvector of $\tilde{\mathbf{A}}$, indicated with $\tilde{\lambda}$ and $\tilde{\mathbf{x}}$ respectively, satisfy

$$
\operatorname{det}(\tilde{\mathbf{A}}(-) \widetilde{\lambda} \mathbf{I})=0
$$

and

$$
(\tilde{\mathbf{A}}(-) \tilde{\lambda} \mathbf{I})(\times) \tilde{\mathbf{x}}=0
$$

where $(-)$ and $(x)$ denote fuzzy subtraction and multiplication, respectively.

The FGM method $[19,39,40]$ can be applied to estimate the relative priority of each critical factor $\left(\widetilde{w}_{i}\right)$ as

$$
\widetilde{w}_{i} \cong \frac{\sqrt[n]{\prod_{j=1}^{n} \tilde{a}_{i j}}}{\sum_{k=1}^{n} \sqrt[n]{\prod_{j=1}^{n} \widetilde{a}_{k j}}}
$$

According to the arithmetic for TFNs, Equation (4) is equivalent to [47]

$$
\begin{aligned}
& w_{i 1} \cong \frac{1}{1+\sum_{k \neq i} \frac{\sqrt[n]{\prod_{j=1}^{n} a_{k j 3}}}{\sqrt[n]{\prod_{j=1}^{n} a_{i j 1}}}} \\
& w_{i 2} \cong \frac{1}{1+\sum_{k \neq i} \frac{\sqrt[n]{\prod_{j=1}^{n} a_{k j 2}}}{\sqrt[n]{\prod_{j=1}^{n} a_{i j 2}}}} \\
& w_{i 3} \cong \frac{1}{1+\sum_{k \neq i} \frac{\sqrt[n]{\prod_{j=1}^{n} a_{k j 1}}}{\sqrt[n]{\prod_{j=1}^{n} a_{i j 3}}}}
\end{aligned}
$$

In addition, the fuzzy maximal eigenvalue $\widetilde{\lambda}_{\max }$ can be estimated as

$$
\widetilde{\lambda}_{\max }=\frac{1}{n} \sum_{i=1}^{n} \frac{\sum_{j=1}^{n}\left(\widetilde{a}_{i j}(\times) \widetilde{w}_{j}\right)}{\widetilde{w}_{i}}
$$

which is decomposed into [48]

$$
\lambda_{\max , 1} \cong 1+\frac{1}{n} \sum_{i=1}^{n} \sum_{j \neq i} \frac{a_{i j 1} w_{j 1}}{w_{i 3}}
$$




$$
\begin{aligned}
& \lambda_{\max , 2} \cong 1+\frac{1}{n} \sum_{i=1}^{n} \sum_{j \neq i} \frac{a_{i j 2} w_{j 2}}{w_{i 2}} \\
& \lambda_{\max , 3} \cong 1+\frac{1}{n} \sum_{i=1}^{n} \sum_{j \neq i} \frac{a_{i j 3} w_{j 3}}{w_{i 1}}
\end{aligned}
$$

The consistency of pairwise comparison results can be evaluated in terms of CR [49]:

$$
\widetilde{C R}=\frac{\frac{\widetilde{\lambda}_{\max }-n}{n-1}}{R I}
$$

where $R I$ is the random consistency index [49]. $\widetilde{C R}$ should be less than 0.1 for a small FAHP problem, or less than 0.3 if the problem size is large or the problem is highly uncertain $[50,51]$.

\subsection{Auto-Weighting FWI for Aggregating the Relative Priorities}

If the (overall) consensus among decision makers exists, FI can be applied to aggregate the relative priorities evaluated by them as follows [23].

Definition 1. The fuzzy intersection (FI) of the relative priorities evaluated by $M$ decision makers for the $i$-th critical factor, indicated with $\widetilde{w}_{i}(1) \sim \widetilde{w}_{i}(M)$, is denoted by $\widetilde{F I}\left(\widetilde{w}_{i}(1), \ldots, \widetilde{w}_{i}(M)\right)$ such that

$$
\mu_{\widetilde{F I}}(x)=\min _{m} \mu_{\widetilde{w}_{i}(m)}(x)
$$

Otherwise, PCFI can be applied to aggregate the relative priorities evaluated by most decision makers $[24,25]$ as follows.

Definition 2. The H/ M partial consensus fuzzy intersection (PCFI) of the relative priorities evaluated by $M$ decision makers for the $i$-th critical factor, indicated with $\widetilde{w}_{i}(1) \sim \widetilde{w}_{i}(M)$, is denoted by $\widetilde{P C F I}^{H / M}\left(\widetilde{w}_{i}(1), \ldots, \widetilde{w}_{i}(M)\right)$ such that

$$
\mu_{\widetilde{P C F I}} H / M(x)=\max _{\text {all } g}\left(\min \left(\mu_{\widetilde{w}_{1}(g(1))}(x), \ldots, \mu_{\widetilde{w}_{1}(g(H))}(x)\right)\right)
$$

where $g() \in Z^{+} ; 1 \leq g() \leq M ; g(p) \cap g(q)=\emptyset \forall p \neq q ; H \geq 2$.

The number of decision makers that reach a consensus is reduced by applying PCFI instead of FI, which is not a favorable property to decision makers. In contrast, FWI [22], as defined below, may find out a consensus without reducing the number of decision makers in this situation.

Definition 3. The fuzzy weighted intersection (FWI) of the relative priorities evaluated by $M$ decision makers for the $i$-th critical factor, indicated with $\widetilde{w}_{i}(1) \sim \widetilde{w}_{i}(M)$, is denoted by $\widetilde{F W} I\left(\widetilde{w}_{i}(1), \ldots, \widetilde{w}_{i}(M)\right)$ such that

$$
\mu_{\widetilde{F W I}}(x)=\min _{m} \mu_{\widetilde{w}_{i}(m)}(x)+\sum_{m}\left(\omega_{m}-\min _{l} \omega_{l}\right)\left(\mu_{\widetilde{w}_{i}(m)}(x)-\min _{l} \mu_{\widetilde{w}_{i}(l)}(x)\right)
$$

where $\omega_{m}$ is the authority level of decision maker $m ; \omega_{m_{1}} \neq \omega_{m_{2}} \exists m_{1} \neq m_{2} ; \sum_{m} \omega_{m}=1$.

However, a prerequisite for applying FWI is that decision makers have unequal authority levels. If decision makers do not discriminate their authority levels, then the proposed methodology assigns 
different authority levels to decision makers automatically based on the CRs of their pairwise comparison results. Let the $C R$ of the pairwise comparison results by expert $m$ be denoted by $\widetilde{C R}(m)$. Obviously,

$$
0 \leq \widetilde{C R}(m) \leq \infty
$$

Since 0.1 is a threshold for $C R$,

$$
\begin{aligned}
& 0 \leq \frac{\widetilde{C R}(m)}{0.1} \leq \infty \\
& 0 \leq e^{-\frac{\widetilde{C R}(m)}{0.1}} \leq 1
\end{aligned}
$$

which is inversely proportional to $\widetilde{C R}(m)$. A smaller value of $\widetilde{C R}(m)$ means higher consistency. Therefore, a reasonable choice of $\omega_{m}$ is

$$
\widetilde{\omega}_{m}=\frac{e^{-\frac{\widetilde{C R}(m)}{0.1}}}{\sum_{q=1}^{M} e^{-\frac{\widetilde{C R}(q)}{0.1}}}
$$

which satisfies the following properties:

(1) $0 \leq \widetilde{\omega}_{m} \leq 1$;

(2) $\sum_{m=1}^{M} \widetilde{\omega}_{m}=1$;

(3) $\widetilde{\omega}_{m} \propto 1 / \widetilde{C R}(m)$, i.e., the lower consistency ratio the higher the authority level.

To simplify the subsequent calculation, only the core of $\widetilde{C R}(m)$ is considered:

$$
\omega_{m}=\frac{e^{-\frac{C R_{2}(m)}{0.1}}}{\sum_{q=1}^{M} e^{-\frac{C R_{2}(q)}{0.1}}}
$$

\subsection{Assessing the Suitability of a Built-in Power Bank for a Smart Backpack Design}

Subsequently, the prevalent FTOPSIS method [40-42] is applied to assess the suitability of a built-in power bank for a smart backpack design. First, the performance of a built-in power bank for a smart backpack design in optimizing each critical factor is normalized using the fuzzy distributive normalization [50]:

$$
\begin{gathered}
\widetilde{\rho}_{q i}=\frac{\widetilde{p}_{q i}}{\sqrt{\sum_{\phi=1}^{Q} \widetilde{p}_{\phi i}^{2}}} \\
=\frac{1}{\sqrt{1+\sum_{\phi \neq q}\left(\frac{\tilde{p}_{\phi i}}{\bar{p}_{q i}}\right)^{2}}}
\end{gathered}
$$

or

$$
\begin{gathered}
\rho_{q i 1}=\frac{1}{\sqrt{1+\sum_{\phi \neq q}\left(\frac{p_{\phi i 3}}{\bar{p}_{q i 1}}\right)^{2}}} \\
\rho_{q i 2}=\frac{1}{\sqrt{1+\sum_{\phi \neq q}\left(\frac{p_{\phi i 2}}{\bar{p}_{q i 2}}\right)^{2}}}
\end{gathered}
$$




$$
\rho_{q i 3}=\frac{1}{\sqrt{1+\sum_{\phi \neq q}\left(\frac{\left.p_{\phi i 1}{ }_{\bar{p}}\right)^{2}}{\bar{p}^{2}}\right.}}
$$

where $\widetilde{p}_{q i}$ is the performance of the $q$-th built-in power bank in optimizing the $i$-th critical factor; $\widetilde{\rho}_{q i}$ is the normalized performance. Subsequently, the fuzzy weighted score is calculated based on the relative priorities derived using the auto-weighting FWI:

$$
\widetilde{s}_{q i}=\widetilde{F W I}\left(\left\{\widetilde{w}_{i}(m)\right\}(\times) \widetilde{\rho}_{q i}\right.
$$

However, $\widetilde{F W} I\left(\left\{\widetilde{w}_{i}(m)\right\}\right.$ is a polygonal fuzzy number, while $\widetilde{p}_{q i}$ is a TFN. Their combination is not easy to calculate. To tackle such complexity, $\widetilde{F W I}\left(\left\{\widetilde{w}_{i}(m)\right\}\right.$ is approximated with a TFN as:

$$
\begin{aligned}
& \widetilde{F W I}\left(\{ \widetilde { w } _ { i } ( m ) \} \cong \left(\operatorname { m i n } \left(\widetilde{F W I}\left(\left\{\widetilde{w}_{i}(m)\right\}\right),\right.\right.\right. \\
& 3 \operatorname{COG}\left(\widetilde{F W I}\left(\left\{\widetilde{w}_{i}(m)\right\}\right)-\max \left(\widetilde{F W} I\left(\left\{\widetilde{w}_{i}(m)\right\}\right)-\min \left(\widetilde{F W I}\left(\left\{\widetilde{w}_{i}(m)\right\}\right)\right. \text {, }\right.\right. \\
& \max \left(\widetilde{F W I}\left(\left\{\widetilde{w}_{i}(m)\right\}\right)\right.
\end{aligned}
$$

as illustrated in Figure 3. In this way, the defuzzified value of the approximating TFN is equal to $\operatorname{COG}\left(\widetilde{F W I}\left(\left\{\widetilde{w}_{i}(m)\right\}\right)\right.$ that is calculated as

$$
\operatorname{COG}\left(\widetilde{F W I}\left(\left\{\widetilde{w}_{i}(m)\right\}\right)=\frac{\int_{\text {all } x} x \mu_{\widetilde{F W I}\left(\left\{\widetilde{w}_{i}(m)\right\}\right.}(x) d x}{\int_{\text {all } x} \mu_{\widetilde{F W I}\left(\left\{\widetilde{w}_{i}(m)\right\}\right.}(x) d x}\right.
$$

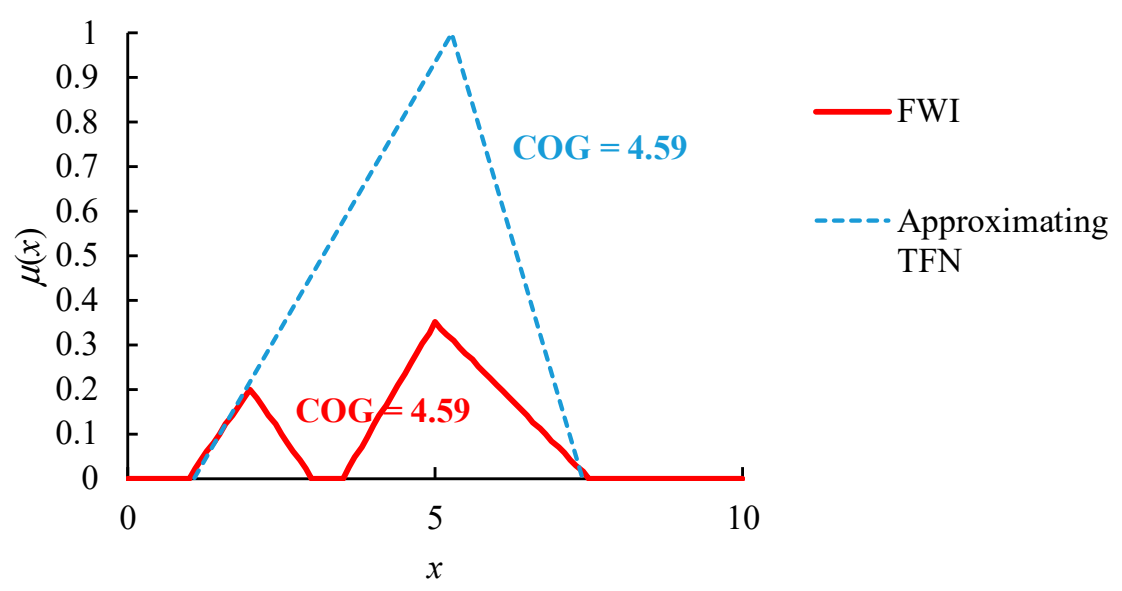

Figure 3. Approximating the fuzzy weighted intersection (FWI) result with a triangular fuzzy number (TFN).

Subsequently, the fuzzy ideal (zenith) point and the fuzzy anti-ideal (nadir) point are specified, respectively, as:

$$
\begin{aligned}
& \widetilde{\Lambda}^{+}=\left\{\widetilde{\Lambda}_{i}^{+}\right\}=\left\{\max _{q} \widetilde{s}_{q i}\right\} \\
& \widetilde{\Lambda}^{-}=\left\{\widetilde{\Lambda}_{i}^{-}\right\}=\left\{\min _{q} \widetilde{s}_{q i}\right\}
\end{aligned}
$$

The fuzzy distance from each built-in power bank to the two points are calculated, respectively, as:

$$
\widetilde{d}_{q}^{+}=\sqrt{\sum_{i=1}^{n} \max \left(\widetilde{\Lambda}_{i}^{+}(-) \widetilde{s}_{q i}, 0\right)^{2}}
$$




$$
\widetilde{d_{q}^{-}}=\sqrt{\sum_{i=1}^{n} \max \left(\widetilde{s}_{q i}(-) \widetilde{\Lambda}_{i}^{-}, 0\right)^{2}}
$$

Finally, the fuzzy closeness of each power bank is obtained as:

$$
\widetilde{C}_{q}=\frac{\widetilde{d_{q}^{-}}}{\widetilde{d_{q}^{+}}(+) \widetilde{d_{q}^{-}}}
$$

A built-in power bank is more suitable if its fuzzy closeness is higher. To get an absolute ranking, the fuzzy closeness can be defuzzified using COG.

\section{Case Study}

\section{Application of the Proposed Methodology}

A backpack company in Taipei City, Taiwan ran a project to investigate the potential opportunities of designing and manufacturing smart backpacks for the domestic market. To this end, the project team started from the selection of suitable built-in power banks for a smart backpack design. This topic is important because built-in power backs are the most common function of smart backpacks [29]. The project team was composed of three members: an industrial engineering professor, a patent analyst, and a smart technology researcher.

In this era, mobile power banks are very prevalent. A user just needs to put a mobile power bank into his/her backpack before going out. Whether it is still necessary to build a power bank in a backpack is questionable. In our view, a built-in power bank is helpful for the following situations:

(1) Marketing needs: if a smart backpack does not have a built-in power bank, it is no different from a normal backpack, because users only need to bring their own mobile power banks.

(2) Protection: in normal backpacks, there is no dedicated space for placing a power bank, which is insufficient for the protection of the mobile power bank.

(3) Convenience: most backpacks are not designed with a power interface, which will cause inconvenience when the user wants to charge. In addition, a smart backpack with a built-in power bank avoids the trouble of forgetting to carry a mobile power bank.

After reviewing the related literature and current practice, the following factors were considered critical to the selection of a built-in power bank for a smart backpack:

- Weight: the lighter the better. According to the experimental results of Heuscher et al. [52], for every $4 \mathrm{~kg}$ increase in the weight of a backpack, the user's chance of lower back pain will increase by $25 \%$. If the weight of the backpack exceeds $10 \%$ of the user's weight, it may also cause long-term lower back pain.

- Battery capacity (mAh): the larger the better;

- Price (cost): the cheaper the better;

- Size: the smaller the better;

- Brand awareness: the higher the better.

These critical factors are not easy to optimize simultaneously and need to be compensated. To evaluate the relative priorities of these critical factors, each decision maker (i.e., project team member) utilized linguistic terms to express his/her belief about the relative priority of a critical factor over another. Based on these beliefs, three fuzzy pairwise comparison matrixes were constructed, as shown in Table 1. 
Table 1. Fuzzy pairwise comparison matrixes constructed by three decision makers.

\begin{tabular}{lccccc}
\hline & $(1,1,1)$ & $(3,5,7)$ & - & $(1,3,5)$ & $(3,5,7)$ \\
\cline { 2 - 6 } Decision Maker \#1 & - & $(1,1,1)$ & - & $(1,3,5)$ & $(3,5,7)$ \\
\cline { 2 - 6 } & $(1,1,3)$ & $(3,5,7)$ & $(1,1,1)$ & $(3,5,7)$ & $(5,7,9)$ \\
\cline { 2 - 6 } & - & - & - & $(1,1,1)$ & - \\
\hline & - & - & - & $(1,3,5)$ & $(1,1,1)$ \\
\cline { 2 - 6 } Decision Maker \#2 & $(1,1,1)$ & - & - & $(1,3,5)$ & - \\
\cline { 2 - 6 } & $(7,9,9)$ & $(1,1,1)$ & $(3,5,7)$ & $(5,7,9)$ & - \\
\cline { 2 - 6 } & $(1,3,5)$ & - & $(1,1,1)$ & $(1,3,5)$ & - \\
\cline { 2 - 6 } & $(1,3,5)$ & $(1,3,5)$ & $(1,3,5)$ & $(1,3,5)$ & $(1,1,1)$ \\
\hline & $(1,1,1)$ & - & - & - & $(1,3,5)$ \\
\hline & $(3,5,7)$ & $(1,1,1)$ & - & $(5,7,9)$ & $(3,5,7)$ \\
\hline & $(7,9,9)$ & $(5,7,9)$ & $(1,1,1)$ & $(5,7,9)$ & $(5,7,9)$ \\
\cline { 2 - 6 } Decision Maker \#3 & $(1,3,5)$ & - & - & $(1,1,1)$ & $(1,3,5)$ \\
\hline
\end{tabular}

Each decision maker applied the FGM method to derive the fuzzy maximal eigenvalue and relative priorities from the corresponding fuzzy pairwise comparison matrix. As a result, the derived fuzzy maximal eigenvalues were

$\tilde{\lambda}_{\max }(1)=(1.732,5.658,32.670)$,

$\widetilde{\lambda}_{\max }(2)=(1.529,5.797,46.753)$, and

$\widetilde{\lambda}_{\max }(3)=(2.137,5.786,23.317)$.

The corresponding consistency ratios were

$\widetilde{C R}(1)=(-0.730,0.147,6.176)$,

$\widetilde{C R}(2)=(-0.775,0.178,9.320)$, and

$\widetilde{C R}(3)=(-0.639,0.176,4.089)$,

showing certain levels of consistency. In addition, the relative priorities evaluated by the decision makers are summarized in Figure 4.

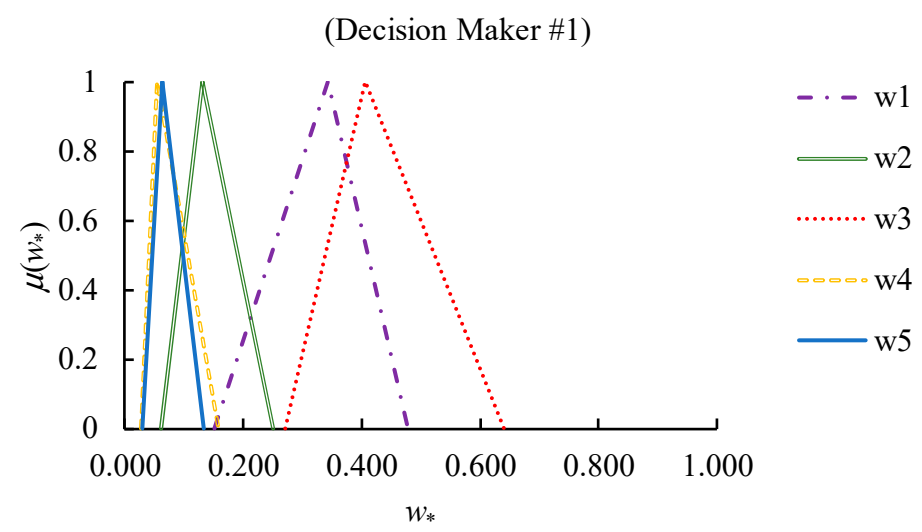

Figure 4. Cont. 

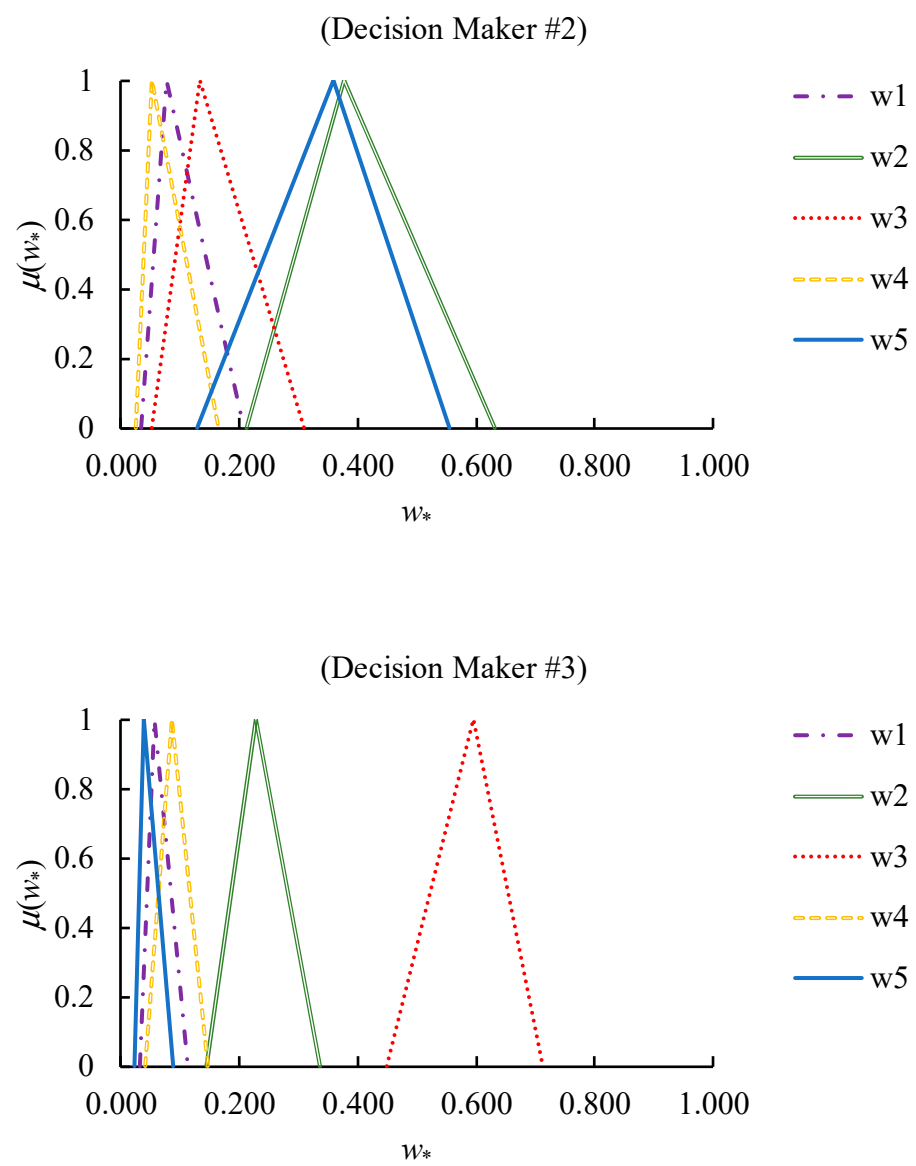

Figure 4. The relative priorities evaluated by the decision makers.

The overall consensus reached by all the decision makers, represented by the FI results of the relative priorities derived by them, are summarized in Figure 5. Obviously, all the decision makers reached an overall consensus regarding the values of $\widetilde{w}_{1}$ and $\widetilde{w}_{2}$. However, an overall consensus regarding the values of other relative priorities was lacking, because the FI results were empty sets. As a result, existing fuzzy group decision-making methods assuming the existence of an overall consensus, such as Lin et al. [1], Chen [15], Chen and Lin [23], Samanlioglu and Kaya [46], and Gao et al. [53] were logically not applicable. To solve this problem, the auto-weighting FWI operator was applied to find out weighted consensus among all decision makers instead. First, the authority levels (or weights) of the decision makers were determined according to Equation (19) as 0.402, 0.295, and 0.302 , respectively.

Based on the assigned authority levels, FWI was applied to aggregate the relative priorities evaluated by the decision makers. The results are summarized in Figure 6.

To facilitate the subsequent calculation, the FWI results were approximated with TFNs according to Equation (26). The approximation results are shown in Figure 7. Obviously, "price" was the most critical factor, followed by "weight". 
$\left(w_{1}\right)$
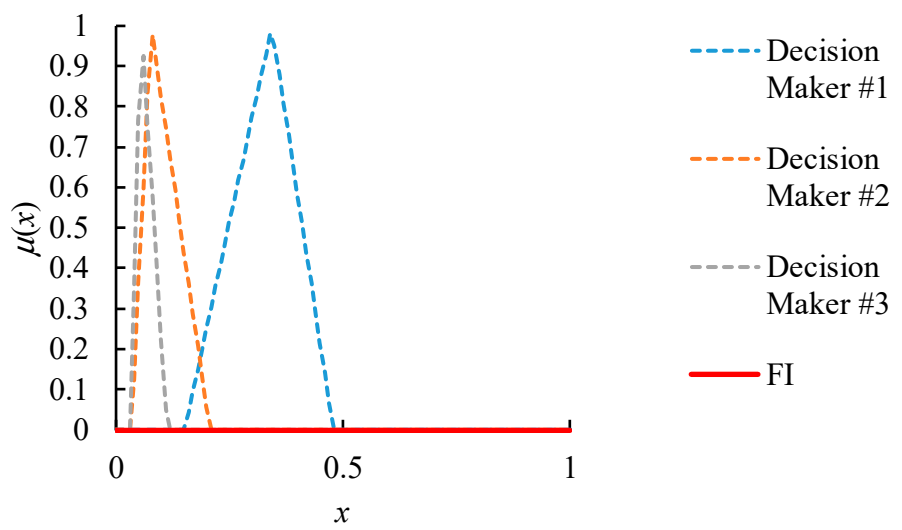

$\left(w_{2}\right)$
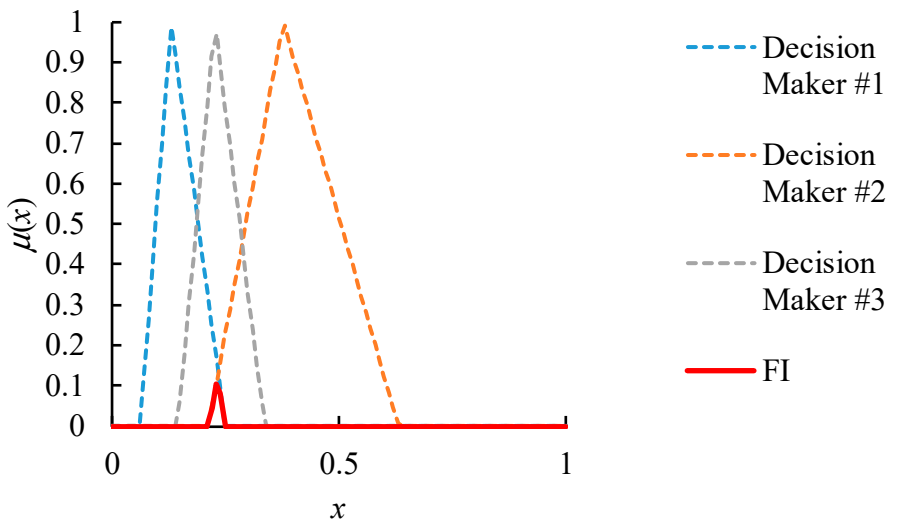

$\left(w_{3}\right)$
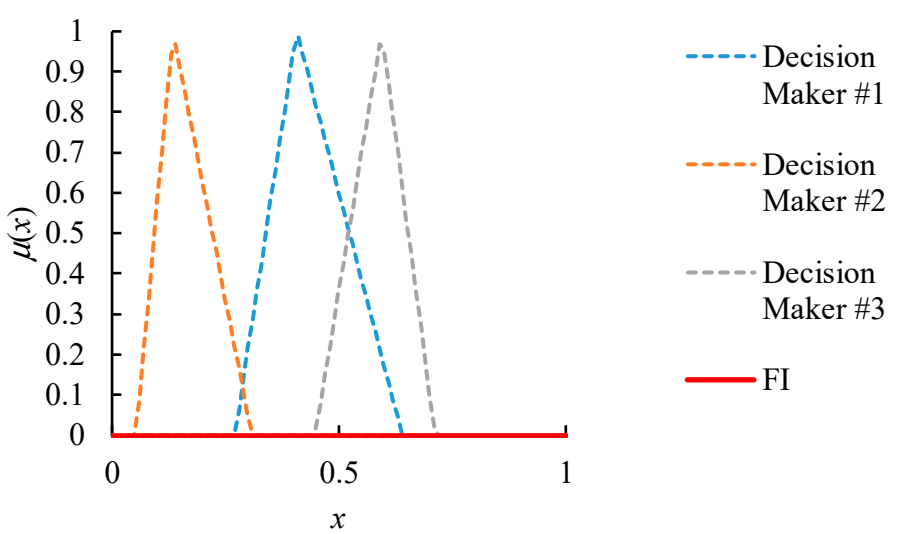

Figure 5. Cont. 
$\left(w_{4}\right)$
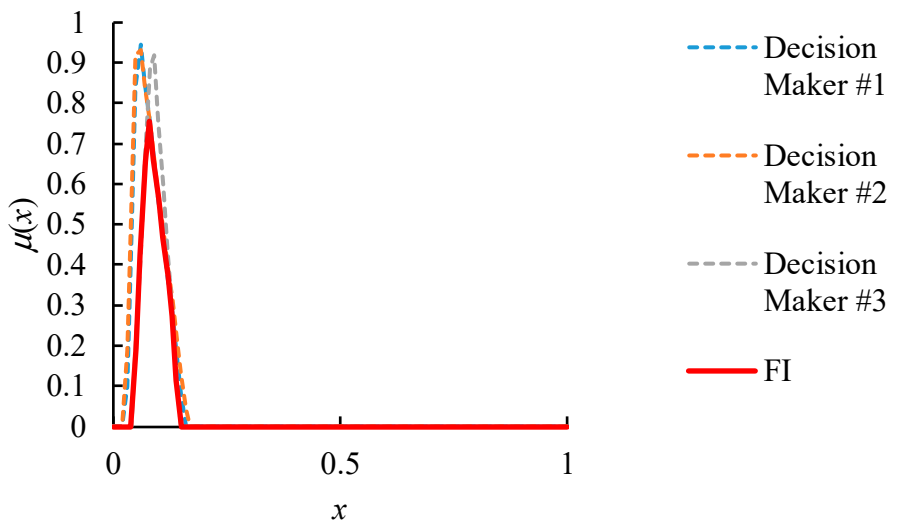

$\left(w_{5}\right)$
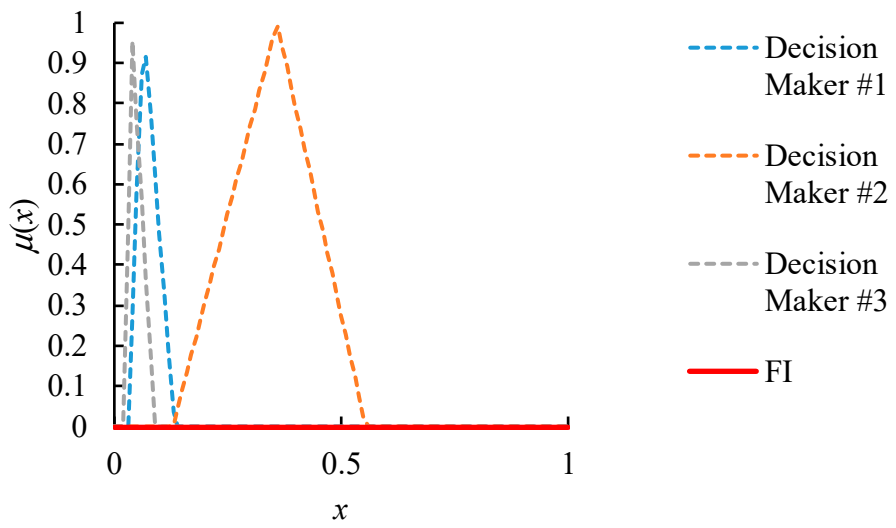

Figure 5. The fuzzy intersection(FI) results of the relative priorities.

$\left(w_{1}\right)$
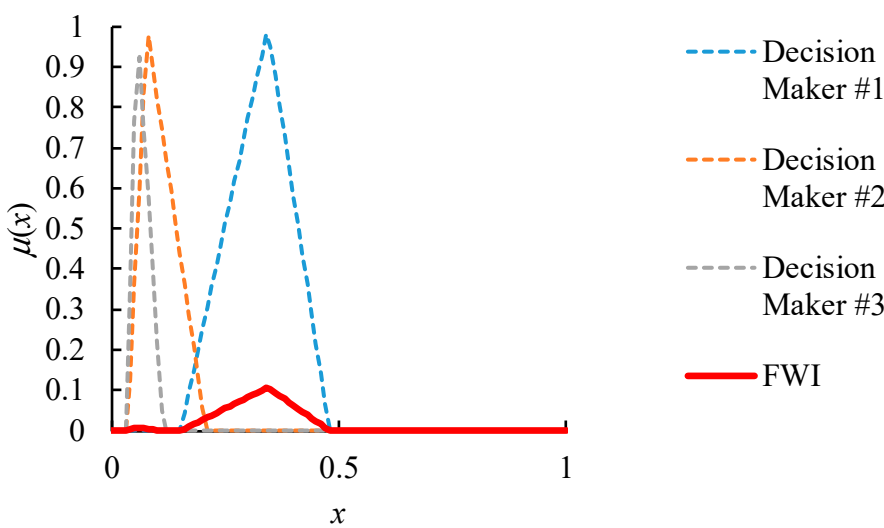

Figure 6. Cont. 
$\left(w_{2}\right)$
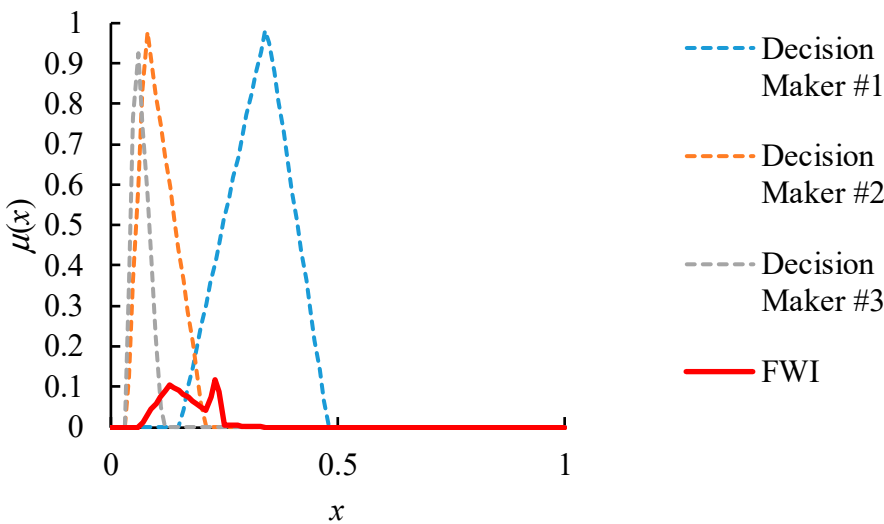

$\left(w_{3}\right)$
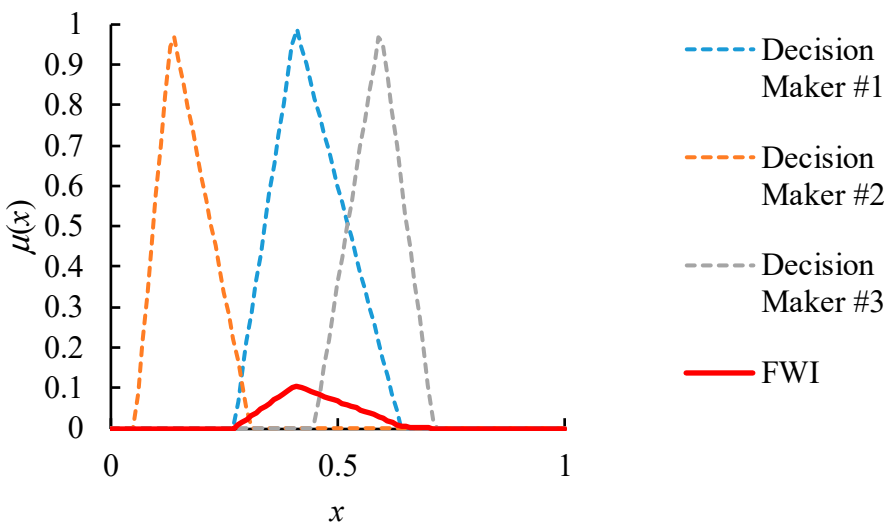

$\left(w_{4}\right)$
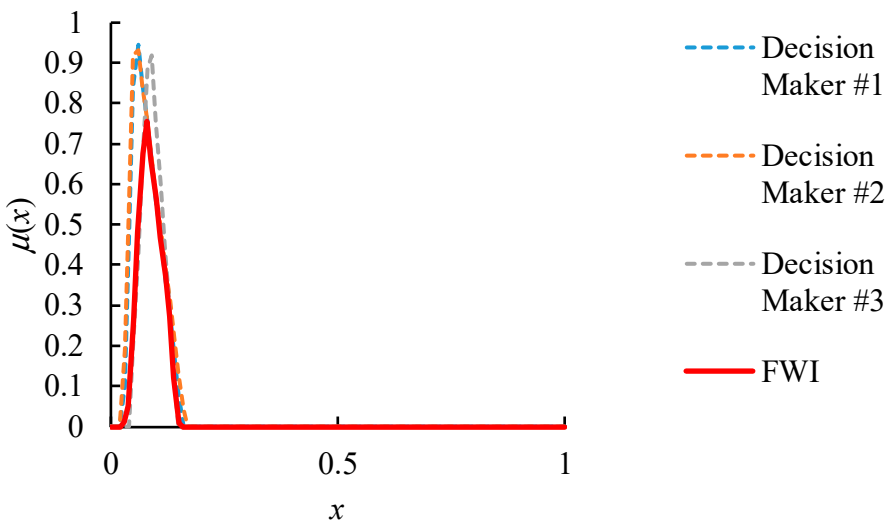

Figure 6. Cont. 
$\left(w_{5}\right)$
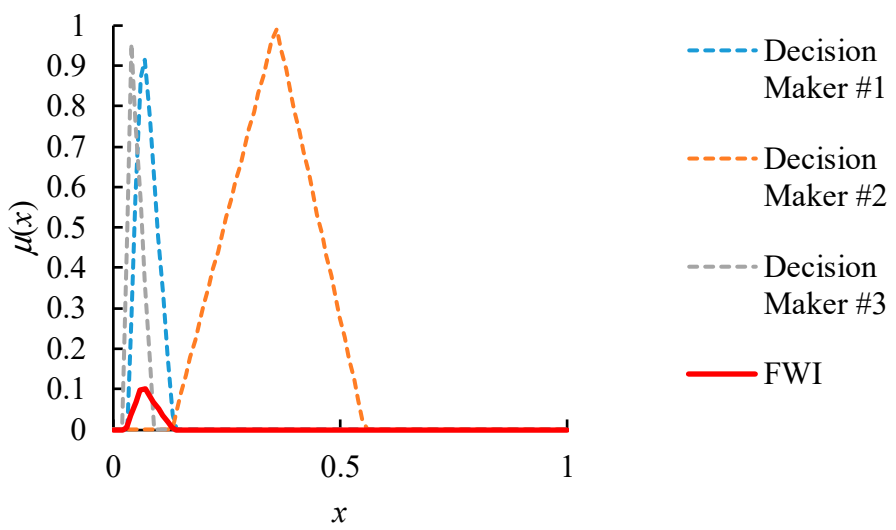

Figure 6. FWI results of the relative priorities based on the assigned authority levels.

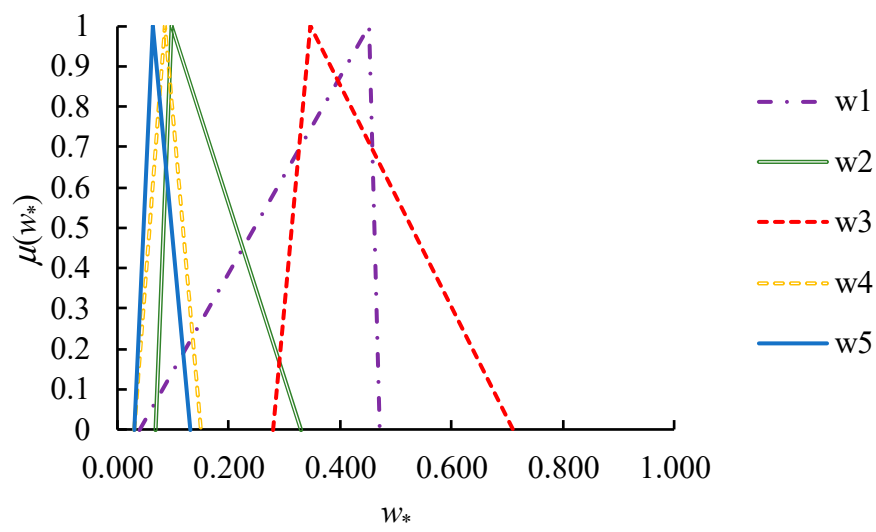

Figure 7. Approximating the FWI results with TFNs.

Among the five critical factors, "battery capacity" and "brand awareness" were the-higher-the-better performance, whereas the others were the-lower-the-better performances. The performances in optimizing these critical factors were evaluated according to the rules depicted in Table 2. The formulation of these rules referred to [36,37].

Based on the derived relative priorities, six existing mobile power banks that met the following requirements were compared:

- Weight less than 200 g;

- $\quad$ Price cheaper than 1000 NTD;

- $\quad$ Battery capacity more than 10,000 mAh;

- Height lower than $20 \mathrm{~mm}$

Table 3 presents the evaluation results. 
Table 2. Rules for evaluating the performances in optimizing critical factors.

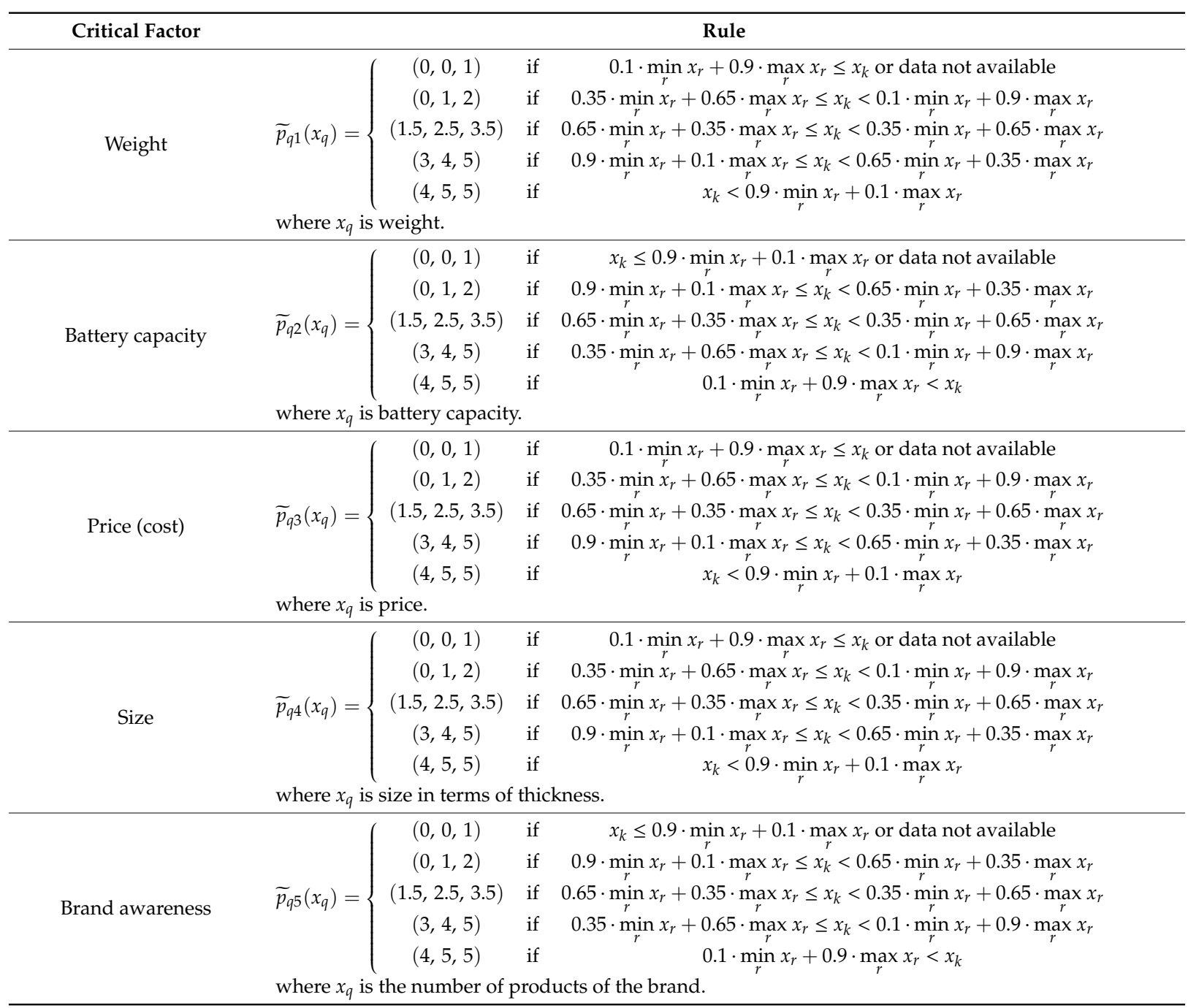


Table 3. Evaluation results.

\begin{tabular}{ccccccc}
\hline $\boldsymbol{q}$ & Mobile Power Bank & Weight $(\mathbf{g})$ & Battery Capacity $\mathbf{( m A h )}$ & Price (NTD) & Size (mm) & Brand Awareness \\
\hline 1 & Asus ZenPower 10000 & $(4,5,5)$ & $(0,0,1)$ & $(0,0,1)$ & $(0,0,1)$ & $(4,5,5)$ \\
2 & iNeno M10 & $(3,4,5)$ & $(0,0,1)$ & $(3,4,5)$ & $(0,1,2)$ & $(0,1,2)$ \\
3 & Esense L100 & $(0,1,2)$ & $(0,0,1)$ & $(3,4,5)$ & $(4,5,5)$ & $(0,0,1)$ \\
4 & iNeno M12 & $(3,4,5)$ & $(4,5,5)$ & $(1.5,2.5,3.5)$ & $(0,1,2)$ & $(0,1,2)$ \\
5 & XDREAM LEADER & $(4,5,5)$ & $(0,0,1)$ & $(3,4,5)$ & $(4,5,5)$ & $(0,0,1)$ \\
6 & 20,000 m ${ }^{-1}$ & $(0,0,1)$ & $(0,0,1)$ & $(4,5,5)$ & $(0,1,2)$ & $(0,0,1)$ \\
\hline
\end{tabular}

Fuzzy TOPSIS was applied to assess the suitability of each mobile power bank. First, the performance of a mobile power bank in optimizing each critical factor was normalized using fuzzy distributive normalization. The results are summarized in Table 4.

Table 4. Normalized performances.

\begin{tabular}{|c|c|c|c|c|c|}
\hline Mobile Power Bank & Weight (g) & Battery Capacity (mAh) & Price (NTD) & Size $(\mathrm{mm})$ & Brand Awareness \\
\hline Asus ZenPower 10000 & $(0.41,0.55,0.65)$ & $(0,0,0.24)$ & $(0,0,0.15)$ & $(0,0,0.17)$ & $(0.77,0.96,1)$ \\
\hline iNeno M10 & $(0.32,0.44,0.62)$ & $(0,0,0.24)$ & $(0.3,0.45,0.64)$ & $(0,0.14,0.33)$ & $(0,0.19,0.45)$ \\
\hline Esense L100 & $(0,0.11,0.27)$ & $(0,0,0.24)$ & $(0.3,0.45,0.64)$ & $(0.54,0.69,0.78)$ & $(0,0,0.24)$ \\
\hline $\begin{array}{l}\text { XDREAM LEADER } \\
20,000 \mathrm{~m}^{-1}\end{array}$ & $(0.41,0.55,0.65)$ & $(0,0,0.24)$ & $(0.3,0.45,0.74)$ & $(0.54,0.69,0.78)$ & $(0,0,0.24)$ \\
\hline tsoe SPB-S10 & $(0,0,0.14)$ & $(0,0,0.24)$ & $(0.39,0.56,0.68)$ & $(0,0.14,0.33)$ & $(0,0,0.24)$ \\
\hline
\end{tabular}

Subsequently, fuzzy weighted scores were calculated based on the derived relative priorities. The results are summarized in Table 5.

Table 5. Fuzzy weighted scores.

\begin{tabular}{|c|c|c|c|c|c|}
\hline Mobile Power Bank & Weight (g) & Battery Capacity (mAh) & Price (NTD) & Size (mm) & Brand Awareness \\
\hline Asus ZenPower 10000 & $(0.02,0.25,0.31)$ & $(0,0,0.08)$ & $(0,0,0.1)$ & $(0,0,0.03)$ & $(0.02,0.06,0.13)$ \\
\hline iNeno M10 & $(0.02,0.04,0.2)$ & $(0,0,0.08)$ & $(0.09,0.16,0.45)$ & $(0,0.01,0.05)$ & $(0,0.01,0.06)$ \\
\hline Esense L100 & $(0,0.01,0.09)$ & $(0,0,0.08)$ & $(0.09,0.16,0.45)$ & $(0.02,0.06,0.12)$ & $(0,0,0.03)$ \\
\hline iNeno M12 & $(0.02,0.04,0.2)$ & $(0.06,0.1,0.33)$ & $(0.04,0.1,0.33)$ & $(0,0.01,0.05)$ & $(0,0.01,0.06)$ \\
\hline $\begin{array}{l}\text { XDREAM LEADER } \\
20,000 \mathrm{~m}^{-1}\end{array}$ & $(0.03,0.05,0.21)$ & $(0,0,0.08)$ & $(0.09,0.16,0.53)$ & $(0.02,0.06,0.12)$ & $(0,0,0.03)$ \\
\hline tsoe SPB-S10 & $(0,0,0.05)$ & $(0,0,0.08)$ & $(0.11,0.2,0.48)$ & $(0,0.01,0.05)$ & $(0,0,0.03)$ \\
\hline
\end{tabular}

Based on the fuzzy weighted scores of all mobile power banks, the fuzzy ideal point and the fuzzy anti-ideal point were defined, as shown in Table 6. Subsequently, the distances from each mobile power bank to the two points were measured, respectively. The results are summarized in Table 7.

Table 6. The fuzzy ideal point and the fuzzy anti-ideal point.

\begin{tabular}{cccccc}
\hline Reference Point & Weight $(\mathbf{g})$ & Battery Capacity $(\mathrm{mAh})$ & Price (NTD) & Size $(\mathbf{m m})$ & Brand Awareness \\
\hline Fuzzy ideal point & $(0.03,0.25,0.31)$ & $(0.06,0.1,0.33)$ & $(0.11,0.2,0.53)$ & $(0.02,0.06,0.12)$ & $(0.02,0.06,0.13)$ \\
Fuzzy anti-ideal point & $(0,0,0.05)$ & $(0,0,0.08)$ & $(0,0,0.1)$ & $(0,0,0.03)$ & $(0,0,0.03)$ \\
\hline
\end{tabular}

Table 7. Distances between each mobile power bank and the two reference points.

\begin{tabular}{ccc}
\hline Mobile Power Bank & $\tilde{\boldsymbol{d}}_{\boldsymbol{q}}^{+}$ & $\tilde{\boldsymbol{d}}_{\boldsymbol{q}}^{-}$ \\
\hline Asus ZenPower 10000 & $(0,0.23,0.63)$ & $(0.82,1.11,1.24)$ \\
iNeno M10 & $(0,0.1,0.44)$ & $(0.34,0.67,1.08)$ \\
Esense L100 & $(0,0.18,0.52)$ & $(0.56,0.83,1.1)$ \\
iNeno M12 & $(0,0,0.42)$ & $(0.84,1.15,1.38)$ \\
XDREAM LEADER 20,000 m ${ }^{-1}$ & $(0,0.12,0.42)$ & $(0.66,0.99,1.31)$ \\
tsoe SPB-S10 & $(0,0.27,0.5)$ & $(0.29,0.58,0.84)$ \\
\hline
\end{tabular}


Finally, the fuzzy closeness of each mobile power bank was derived. The results are shown in Table 8.

Table 8. Fuzzy closeness of each mobile power bank.

\begin{tabular}{|c|c|}
\hline Mobile Power Bank & $\tilde{C}_{q}$ \\
\hline Asus ZenPower 10000 & $(0.56,0.83,1)$ \\
\hline iNeno M10 & $(0.44,0.87,1)$ \\
\hline Esense L100 & $(0.52,0.82,1)$ \\
\hline iNeno M12 & $(0.67,1,1)$ \\
\hline XDREAM LEADER 20,000 $\mathrm{m}^{-1}$ & $(0.61,0.9,1)$ \\
\hline tsoe SPB-S10 & $(0.36,0.68,1)$ \\
\hline
\end{tabular}

Subsequently, COG was applied to defuzzify the fuzzy closeness of each mobile power bank. The results are summarized in Table 9.

Table 9. Defuzzification results.

\begin{tabular}{cc}
\hline Mobile Power Bank & Defuzzified Closeness \\
\hline Asus ZenPower 10000 & 0.798 \\
iNeno M10 & 0.770 \\
Esense L100 & 0.779 \\
iNeno M12 & 0.889 \\
XDREAM LEADER 20,000 m & -1 \\
tsoe SPB-S10 & 0.836 \\
\hline
\end{tabular}

According to the experimental results, the following discussion was made:

(1) The top performing mobile power bank was iNeno M12, showing that it was the most suitable choice among the six compared mobile power backs, which was obviously due to its high battery capacity and low weight.

(2) In contrast, tsoe SPB-S10 had the worst overall performance, and was considered the least suitable, owing to its heavy weight and low brand awareness.

(3) For comparison, the FGM-FGM-fuzzy weighted average (FWA) approach [3,21] was also applied to compare the mobile power banks, in which decision makers' pairwise comparison results were aggregated using FGM. Then, FGM was also applied to derive the relative priorities of the critical factors from the aggregation result. Finally, FWA was applied to assess the overall performance of a mobile power bank that was defuzzified using COG. The results are summarized in Table 10. The top performing mobile power bank was also iNeno M12, conforming to the conclusion drawn using the proposed methodology. However, the least suitable mobile power bank was Asus ZenPower 10000, rather than tsoe SPB-S10.

Table 10. Assessment results using fuzzy geometric mean-fuzzy geometric mean-fuzzy weighted average (FGM-FGM-FWA).

\begin{tabular}{cc}
\hline Mobile Power Bank & Defuzzified Overall Performance \\
\hline Asus ZenPower 10,000 & 1.84 \\
iNeno M10 & 2.93 \\
Esense L100 & 2.67 \\
iNeno M12 & 3.57 \\
XDREAM LEADER 20,000 m & -1 \\
tsoe SPB-S10 & 3.21 \\
\hline
\end{tabular}


(4) The ranking results using the two methods are compared in Figure 8. There were considerable differences between the ranking results using the two methods. One possible reason for this was that the FGM-FGM-FWA approach assigned a heavier weight to battery capacity about which the overall consensus among decision makers was insufficient.

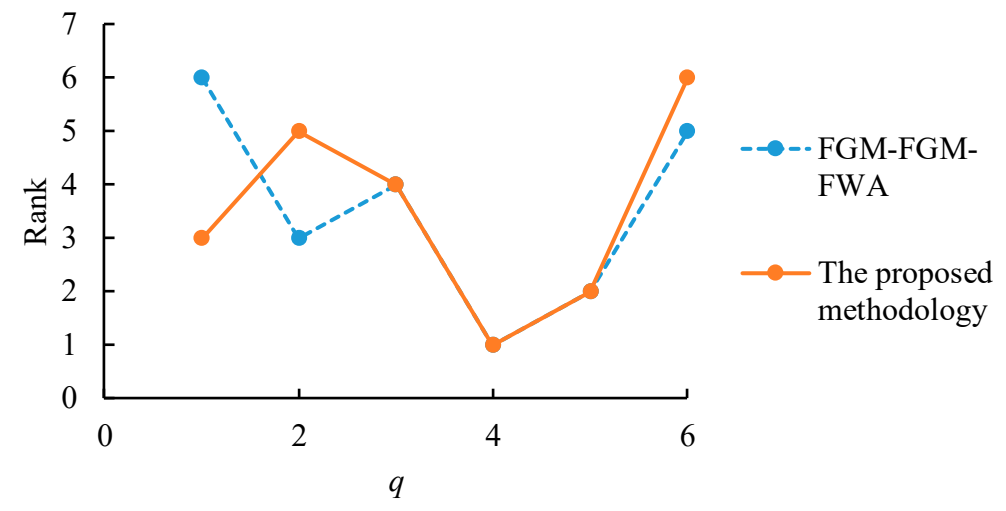

Figure 8. Comparison of the ranking results.

(5) In this experiment, decision makers lacked an overall consensus. The FGM-FGM-FWA method could not deal with this problem, but it directly aggregated decision makers' judgments. The result obtained in this way was unconvincing. In contrast, the proposed methodology reasonably adjusted the weights of decision makers to generate an overall consensus. The weight of a decision maker was proportional to the consistency of his/her judgment. In this way, the selection result would be more convincing. This is the advantage of the proposed methodology over the FGM-FGM-FWA method.

\section{Conclusions}

Smart technology applications are penetrating into our daily lives. Smart backpacks with built-in power backs are one of the most prevalent smart technology applications. However, selecting a suitable mobile power back for a smart backpack design is a challenging task, because the designer has to make a trade-off among several critical factors. To address this challenge, an auto-weighting fuzzy-weighted-intersection FAHP approach is proposed in this study. The auto-weighting fuzzy-weighted-intersection FAHP approach aggregates multiple decision makers' judgments in a reasonable manner when an overall consensus among these decision makers is lacking. Compared to the existing methods based on PCFI that seek the partial consensus of only some experts, the auto-weighting fuzzy-weighted-intersection FAHP approach applies the FWI operator by specifying decision makers' authority levels according to the consistency ratios of their judgments, so that the number of decision makers that reach a consensus is not reduced. In this way, the group decision-making result will be more acceptable to all decision makers.

The proposed methodology has been applied to compare six existing mobile power banks for a smart backpack design to illustrate its applicability. After analyzing the experimental results, the following conclusions were drawn:

(1) Among the six compared mobile power banks for a smart backpack design, iNeno M12, a mobile power back with high battery capacity and low weight, was evaluated as the most suitable built-in power bank. In contrast, tsoe SPB-S10 was considered the least suitable owing to the low awareness of the brand.

(2) The ranking result using the proposed methodology was slightly different from that using an existing method. The reason was that whether an overall consensus existed among decision makers was not emphasized in the existing method. 
However, the proposed methodology is also subject to some limitations. First, although the auto-weighting mechanism seems reasonable, it may not be acceptable to all decision makers. In addition, it is possible that a more authoritative decision maker makes a less consistent judgment.

Some directions for future research are provided as follows. First, there are other ways to assign authority levels to decision makers automatically. It is also possible to hybridize the subjective and objective authority levels of decision makers [54-56]. In addition, agents can be adopted to facilitate the collaboration process $[57,58]$. Further, other power generation mechanisms, such as solar panels and friction-induced vibration $[59,60]$, can also be compared for a smart backpack design.

Author Contributions: Data curation, methodology and writing original draft: H.-C.W., T.-C.T.C., C.-H.H., Y.-C.S.; writing-review and editing: H.-C.W. and T.-C.T.C. All authors contributed equally to the writing of this paper. All authors have read and agreed to the published version of the manuscript.

Funding: This study was partly funded by Ministry of Science and Technology, Taiwan.

Conflicts of Interest: The authors declare no conflict of interest.

\section{References}

1. Lin, Y.C.; Wang, Y.C.; Chen, T.C.T.; Lin, H.F. Evaluating the suitability of a smart technology application for fall detection using a fuzzy collaborative intelligence approach. Mathematics 2019, 7, 1097. [CrossRef]

2. Shapiro, J.M. Smart cities: Quality of life, productivity, and the growth effects of human capital. Rev. Econ. Stat. 2006, 88, 324-335. [CrossRef]

3. Chen, T. Assessing factors critical to smart technology applications in mobile health care-The FGM-FAHP approach. Health Policy Technol. 2020, 9, 194-203. [CrossRef]

4. Chen, T.; Chiu, M.C. Smart technologies for assisting the life quality of persons in a mobile environment: A review. J. Ambient Intell. Humaniz. Comput. 2018, 9, 319-327. [CrossRef]

5. Persistence Market Research. Smart Backpack Market: Global Industry Trend Analysis 2013 to 2017 and Forecast 2018-2028. Available online: https://www.persistencemarketresearch.com/market-research/smartbackpack-market.asp (accessed on 7 October 2020).

6. Chen, T.C.T.; Chaovalitwongse, W.A.; O'grady, M.J.; Honda, K. Smart technologies for improving the quality of mobile health care. Health Care Manag. Sci. 2020, 23, 171-172. [CrossRef] [PubMed]

7. Lin, Y.C.; Chen, T. A multibelief analytic hierarchy process and nonlinear programming approach for diversifying product designs: Smart backpack design as an example. Proc. Inst. Mech. Eng. Part B J. Eng. Manuf. 2020, 234, 1044-1056. [CrossRef]

8. Javanbarg, M.B.; Scawthorn, C.; Kiyono, J.; Shahbodaghkhan, B. Fuzzy AHP-based multicriteria decision making systems using particle swarm optimization. Expert Syst. Appl. 2012, 39, 960-966. [CrossRef]

9. Kubler, S.; Robert, J.; Derigent, W.; Voisin, A.; Le Traon, Y. A state-of the-art survey \& testbed of fuzzy AHP (FAHP) applications. Expert Syst. Appl. 2016, 65, 398-422.

10. Zhang, W.G.; Mei, Q.; Lu, Q.; Xiao, W.L. Evaluating methods of investment project and optimizing models of portfolio selection in fuzzy uncertainty. Comput. Ind. Eng. 2011, 61, 721-728. [CrossRef]

11. Wang, Y.C.; Chen, T.C.T. A partial-consensus posterior-aggregation FAHP method-Supplier selection problem as an example. Mathematics 2019, 7, 179. [CrossRef]

12. Pedrycz, W. Collaborative architectures of fuzzy modeling. Lect. Notes Comput. Sci. 2008, 5050, 117-139.

13. Chen, T.; Liao, T.W.; Yu, F. Fuzzy collaborative intelligence and systems. Int. J. Intell. Syst. 2015, 30, 617-619. [CrossRef]

14. Mitra, S.; Banka, H.; Pedrycz, W. Rough-fuzzy collaborative clustering. IEEE Trans. Syst. ManCybern. Part B (Cybern.) 2006, 36, 795-805. [CrossRef] [PubMed]

15. Chen, T. A heterogeneous fuzzy collaborative intelligence approach for forecasting the product yield. Appl. Soft Comput. 2017, 57, 210-224. [CrossRef]

16. Yu, C.S. A GP-AHP method for solving group decision-making fuzzy AHP problems. Comput. Oper. Res. 2002, 29, 1969-2001. [CrossRef]

17. Jaskowski, P.; Biruk, S.; Bucon, R. Assessing contractor selection criteria weights with fuzzy AHP method application in group decision environment. Autom. Constr. 2010, 19, 120-126. [CrossRef] 
18. Roghanian, E.; Rahimi, J.; Ansari, A. Comparison of first aggregation and last aggregation in fuzzy group TOPSIS. Appl. Math. Model. 2010, 34, 3754-3766. [CrossRef]

19. Zheng, G.; Zhu, N.; Tian, Z.; Chen, Y.; Sun, B. Application of a trapezoidal fuzzy AHP method for work safety evaluation and early warning rating of hot and humid environments. Saf. Sci. 2012, 50, 228-239. [CrossRef]

20. Kahraman, C.; Ruan, D.; Doğan, I. Fuzzy group decision-making for facility location selection. Inf. Sci. 2003, 157, 135-153. [CrossRef]

21. Wang, Y.C.; Chen, T.; Yeh, Y.L. Advanced 3D printing technologies for the aircraft industry: A fuzzy systematic approach for assessing the critical factors. Int. J. Adv. Manuf. Technol. 2019, 105, 4059-4069. [CrossRef]

22. Chen, T.C.T.; Wang, Y.C.; Lin, C.W. A fuzzy collaborative forecasting approach considering experts' unequal levels of authority. Appl. Soft Comput. 2020, 106455. [CrossRef]

23. Chen, T.; Lin, Y.C. A fuzzy-neural system incorporating unequally important expert opinions for semiconductor yield forecasting. Int. J. Uncertain. Fuzziness Knowl.-Based Syst. 2008, 16, 35-58. [CrossRef]

24. Chen, T. A hybrid fuzzy and neural approach with virtual experts and partial consensus for DRAM price forecasting. Int. J. Innov. Comput. Inf. Control. 2012, 8, 583-597.

25. Chen, T.C.T.; Wang, Y.C.; Huang, C.H. An evolving partial consensus fuzzy collaborative forecasting approach. Mathematics 2020, 8, 554. [CrossRef]

26. Kacprzyk, J.; Fedrizzi, M. A 'soft' measure of consensus in the setting of partial (fuzzy) preferences. Eur. J. Oper. Res. 1988, 34, 316-325. [CrossRef]

27. Chen, T.C.T.; Wu, H.C. Forecasting the unit cost of a DRAM product using a layered partial-consensus fuzzy collaborative forecasting approach. Complex Int. Syst. 2020, 6, 479-492. [CrossRef]

28. Foroudi, P.; Gupta, S.; Sivarajah, U.; Broderick, A. Investigating the effects of smart technology on customer dynamics and customer experience. Comput. Hum. Behav. 2018, 80, 271-282. [CrossRef]

29. Johnson, N.; Turner, A.-M. Best Smart Backpacks in 2020. Available online: https://www.imore.com/bestsmart-backpacks (accessed on 14 September 2020).

30. Lee, J.H.; Kim, K.; Lee, S.C.; Shin, B.S. Smart backpack for visually impaired person. In Proceedings of the International Conference on ICT for Smart Society, Jakarta, Indonesia, 13-14 June 2013; pp. 1-4.

31. Chen, T.; Honda, K. Solving data preprocessing problems in existing location-aware systems. J. Ambient Intell. Humaniz. Comput. 2018, 9, 253-259. [CrossRef]

32. Chen, T. Enhancing the performance of a ubiquitous location-aware service system using a fuzzy collaborative problem solving strategy. Comput. Ind. Eng. 2015, 87, 296-307. [CrossRef]

33. Chandrasekhar, A.; Alluri, N.R.; Vivekananthan, V.; Purusothaman, Y.; Kim, S.J. A sustainable freestanding biomechanical energy harvesting smart backpack as a portable-wearable power source. J. Mater. Chem. C 2017, 5, 1488-1493. [CrossRef]

34. Cruz, F.R.G.; Yumang, A.N.; Mañalac, J.E.P.B.; Cañete, K.K.M.L.; Milambiling, J.D. Smart backpack for the blind with light sensors, ZigBee, RFid for grid-based selection. AIP Conf. Proc. 2018, 2045, 020054.

35. Sankhe, P.; Rodrigues, E. Smart backpack. In Proceedings of the 2018 3rd International Conference for Convergence in Technology, Pune, India, 6-8 April 2018; pp. 1-4.

36. Wu, H.C.; Chen, T.; Huang, C.H. A piecewise linear FGM approach for efficient and accurate FAHP analysis: Smart backpack design as an example. Mathematics 2020, 8, 1319. [CrossRef]

37. Chen, T.C.T.; Lin, Y.C. Diverse three-dimensional printing capacity planning for manufacturers. Robot. Comput.-Integr. Manuf. 2021, 67, 102052. [CrossRef]

38. Wang, Y.C.; Chen, T.; Lin, C.W. A slack-diversifying nonlinear fluctuation smoothing rule for job dispatching in a wafer fabrication factory. Robot. Comput.-Integr. Manuf. 2013, 29, 41-47. [CrossRef]

39. Buckley, J.J. Fuzzy hierarchical analysis. Fuzzy Sets Syst. 1985, 17, 233-247. [CrossRef]

40. Sirisawat, P.; Kiatcharoenpol, T. Fuzzy AHP-TOPSIS approaches to prioritizing solutions for reverse logistics barriers. Comput. Ind. Eng. 2018, 117, 303-318. [CrossRef]

41. Chen, T.C.T.; Lin, Y.C. A FAHP-FTOPSIS approach for bioprinter selection. Health Technol. 2020, 1-13. [CrossRef]

42. Aydogan, E.K. Performance measurement model for Turkish aviation firms using the rough-AHP and TOPSIS methods under fuzzy environment. Expert Syst. Appl. 2011, 38, 3992-3998. [CrossRef]

43. van Broekhoven, E.; De Baets, B. Fast and accurate center of gravity defuzzification of fuzzy system outputs defined on trapezoidal fuzzy partitions. Fuzzy Sets Syst. 2006, 157, 904-918. [CrossRef] 
44. Hoseini, P.; Khoei, A.; Hadidi, K. Circuit design of voltage mode center of gravity defuzzifier in CMOS process. In Proceedings of the 2010 International Conference on Electronic Devices, Systems and Applications, Kuala Lumpur, Malaysia, 11-14 April 2010; pp. 169-173.

45. Chen, T.C.T. Guaranteed-consensus posterior-aggregation fuzzy analytic hierarchy process method. Neural. Comput. Appl. 2020, 32, 7057-7068. [CrossRef]

46. Samanlioglu, F.; Kaya, B.E. Evaluation of the COVID-19 pandemic intervention strategies with hesitant F-AHP. J. Healthc. Eng. 2020, 2020, 8835258.

47. Hanss, M. Applied Fuzzy Arithmetic; Springer: Berlin/Heidelberg, Germany, 2005.

48. Chen, T.C.T.; Honda, K. Fuzzy Collaborative Forecasting and Clustering: Methodology, System Architecture, and Applications; Springer Nature Switzerland AG: Cham, Switzerland, 2019.

49. Saaty, T.L. Axiomatic foundation of the analytic hierarchy process. Manag. Sci. 1986, 32, 841-855. [CrossRef]

50. Phong, N.T.; Phuc, V.N.; Quyen, T.T.H.L.N. Application of fuzzy analytic network process and TOPSIS method for material supplier selection. Key Eng. Mater. 2017, 728, 411-415. [CrossRef]

51. Wedley, W.C. Consistency prediction for incomplete AHP matrices. Math. Comput. Model. 1993, 17, $151-161$. [CrossRef]

52. Heuscher, Z.; Gilkey, D.P.; Peel, J.L.; Kennedy, C.A. The association of self-reported backpack use and backpack weight with low back pain among college students. J. Manip. Physiol. Ther. 2010, 33, 432-437. [CrossRef]

53. Gao, H.; Ju, Y.; Gonzalez, E.D.S.; Zhang, W. Green supplier selection in electronics manufacturing: An approach based on consensus decision making. J. Clean. Prod. 2020, 245, 118781. [CrossRef]

54. Chen, T.; Wang, Y.C. A nonlinear scheduling rule incorporating fuzzy-neural remaining cycle time estimator for scheduling a semiconductor manufacturing factory-A simulation study. Int. J. Adv. Manuf. Technol. 2009, 45, 110-121. [CrossRef]

55. Pedrycz, W. Collaborative fuzzy clustering. Pattern Recognit. Lett. 2002, 23, 1675-1686. [CrossRef]

56. Chen, T.; Jeang, A.; Wang, Y.C. A hybrid neural network and selective allowance approach for internal due date assignment in a wafer fabrication plant. Int. J. Adv. Manuf. Technol. 2008, 36, 570-581. [CrossRef]

57. Chen, T.; Wang, Y.C. An agent-based fuzzy collaborative intelligence approach for precise and accurate semiconductor yield forecasting. IEEE Trans. Fuzzy Syst. 2013, 22, 201-211. [CrossRef]

58. Chen, T.; Wang, Y.C. An evolving fuzzy planning mechanism for a ubiquitous manufacturing system. Int. J. Adv. Manuf. Technol. 2020, 108, 2337-2347. [CrossRef]

59. Shweta, M.; Tanvi, P.; Poonam, S.; Nilashree, M. Multipurpose smart bag. Procedia Comput. Sci. 2016, 79, 77-84. [CrossRef]

60. Tadokoro, C.; Matsumoto, A.; Nagamine, T.; Sasaki, S. Piezoelectric power generation using friction-induced vibration. Smart Mater. Struct. 2017, 26, 065012. [CrossRef]

Publisher's Note: MDPI stays neutral with regard to jurisdictional claims in published maps and institutional affiliations.

(C) 2020 by the authors. Licensee MDPI, Basel, Switzerland. This article is an open access article distributed under the terms and conditions of the Creative Commons Attribution (CC BY) license (http://creativecommons.org/licenses/by/4.0/). 